\title{
PROPAGAÇÃO DE JABUTICABEIRA POR ESTAQUIA ${ }^{1}$
}

\author{
SIMONE APARECIDA ZOLET SASSO², IDEMIR CITADIN ${ }^{3}$, MOESES ANDRIGO DANNER ${ }^{4}$
}

RESUMO - O objetivo deste trabalho foi investigar a eficiência da estaquia na produção de mudas de jabuticabeira (Plinia cauliflora). Testou-se a eficácia de enraizamento de estacas lenhosas, utilizando quatro concentrações de ácido indolbutírico (AIB) $\left(0 ; 2.000 ; 4.000\right.$ e $\left.6.000 \mathrm{mg} \mathrm{L}^{-1}\right)$ e dois procedimentos (corte vertical e anelamento da estaca); e o enraizamento de estacas apicais herbáceas, utilizando cinco concentrações de AIB (0; 2.000; 4.000; 6.000 e $8.000 \mathrm{mg} \mathrm{L}^{-1}$ ) e em duas épocas (outubro e dezembro de 2007). O enraizamento das estacas foi avaliado após 180 dias da implantação dos experimentos. Observou-se que o enraizamento de estacas lenhosas é dependente da aplicação de AIB, sendo que o maior percentual de enraizamento (50\%) foi obtido na maior concentração de AIB $\left(6.000 \mathrm{mg} \mathrm{L}^{-1}\right)$ conjugada com o corte vertical. Para as estacas apicais herbáceas, o enraizamento foi baixo (máximo de 10\%), entretanto há o potencial de enraizamento e, por isso, ajustes na técnica devem ser testados para maximizá-lo.

Termos para indexação: Plinia cauliflora, produção de mudas, enraizamento, AIB.

\section{CUTTING PROPAGATION OF JABUTICABA TREE}

\begin{abstract}
The objective of this work was to test the efficiency of cutting technique for the propagation of Jabuticaba tree (Plinia cauliflora). The rooting potential of wood cutting was tested, using four concentrations of Indolbutiric Acid - IBA (0, 2000 , 4000 and $\left.6000 \mathrm{mg} \mathrm{L}^{-1}\right)$ and two procedures (cross section and cutting girdling). Also the rooting potential of softwood terminal cuttings was tested, using five concentrations of IBA $\left(0,2000,4000,6000\right.$ and $\left.8000 \mathrm{mg} \mathrm{L}^{-1}\right)$ in two periods of implantation (October and December 2007). The rooting percentage was evaluated 180 days after the experiment started. It was observed that rooting of wood cutting is dependent on the application of IBA, so the biggest rooting percentage $(50 \%)$ was obtained in the biggest concentration of IBA $\left(6000 \mathrm{mg} \mathrm{L}^{-1}\right)$ associated with cross section. For the softwood terminal cuttings, the rooting percentage was smaller (maximum of $10 \%$ ), however there is the potential of rooting, so adjustments in the technique must be tested for maximization.
\end{abstract}

Index terms: Plinia sp., plant propagation, rooting, IBA.

\section{INTRODUÇÃO}

A jabuticabeira é originária do centro/sul/ sudeste do Brasil, pertence à família Myrtaceae e gênero Myrciaria (Mattos, 1983). Porém, houve uma alteração nomenclatural do gênero Myrciaria (BERG, 1857) para Plinia, a qual foi proposta por Sobral (1985) e utilizada por Mattos (1998) para reclassificar as espécies de jabuticabeira.

Segundo Mattos (1983), são conhecidas nove espécies de jabuticabeira, dentre as quais se destaca Plinia cauliflora (DC) Berg, conhecida como jabuticaba-paulista ou jabuticaba-açu. Esta espécie apresenta dispersão natural em alguns municípios da região sudoeste do Paraná.
O potencial de comercialização da jabuticaba é grande em função de suas características organolépticas (MAGALHÃES et al., 1996), sendo apreciada tanto para consumo in natura como para a fabricação de geleia, suco, sorvete, bebidas fermentadas e licores.

Entretanto, um dos maiores problemas enfrentados para a expansão do cultivo de jabuticabeira é o alto custo das mudas, devido principalmente à dificuldade de enraizamento de estacas (LEONEL et al., 1991; DUARTE et al., 1997; SCARPARE FILHO et al., 1999; CASAGRANDE JR. et al., 2000; SCARPARE et al., 2002; PEREIRA et al., 2005). Por isso, a principal forma de obtenção de mudas da espécie ainda é por sementes, o que desestimula seu

${ }^{1}$ (Trabalho 109-09). Recebido em: 04-05-2009. Aceito para publicaçaõ em: 13-01-2010. Parte da Dissertação de Mestrado ${ }^{2}$ Eng $^{\mathrm{a}}$. Agra., MSc. UTFPR, Campus Pato Branco. iosasso@ibest.com.br

${ }^{3}$ Eng. Agr., Dr., Professor Titular, UTFPR, Campus Pato Branco. Via do conhecimento, km 01, Pato Branco-PR. 85503-390 idemir@utfpr.edu.br - autor para correspondência

${ }^{4}$ Eng. Agr., MSc. Doutorando UFPR, Bolsista CAPES. Professor Substituto, UTFPR, Campus Pato Branco. moesesandrigo@yahoo.com.br 
cultivo, visto que a planta demora de oito a 15 anos para entrar em produção (MATTOS, 1983). O uso da estaquia na formação de mudas poderá garantir a antecipação do período reprodutivo, que é uma vantagem da propagação vegetativa, e contribuir para a exploração econômica da jabuticabeira. Além disso, a propagação proporciona a manutenção das características da planta-matriz nos descendentes, assegurando a formação de pomares comerciais homogêneos, facilitando o manejo do cultivo.

Em jabuticabeira, a estaquia é empregada empiricamente por agricultores e viveiristas, utilizando ramos de grande porte, o que acarreta grande dano à planta-matriz. Entretanto, deve-se dar uma abordagem analítica a esta técnica, pois não são documentados na literatura altos percentuais de enraizamento de estacas herbáceas. Até o momento, o maior percentual foi obtido por Duarte et al. (1997), que verificaram até $60 \%$ de enraizamento de estacas apicais herbáceas de $P$. cauliflora, tratadas com 1.000 $\mathrm{mg} \mathrm{L}^{-1}$ de AIB e colocadas em câmara de polietileno hermeticamente fechada, sob $50 \%$ de sombreamento.

Dessa forma, justificam-se trabalhos visando a aperfeiçoar as técnicas de estaquia para jabuticabeira, para obter maiores índices de enraizamento e um método que facilite a obtenção de grande número de mudas, auxiliando no desenvolvimento de cultivos comerciais.

Assim, o objetivo deste trabalho foi investigar a eficiência da estaquia na produção de mudas de jabuticabeira.

\section{MATERIAL E MÉTODOS}

Foram realizados dois experimentos, um utilizando estacas lenhosas e o outro utilizando estacas apicais herbáceas de jabuticabeira.

Experimento 1: Propagação de jabuticabeira por estacas lenhosas

As estacas foram coletadas de planta-matriz de jabuticabeira (P. cauliflora) em idade produtiva, no município de Vitorino-PR. Foram utilizados ramos lenhosos, com folhagem abundante, diâmetro entre 1,5 a $2,0 \mathrm{~cm}$ e comprimento de 100 a $120 \mathrm{~cm}$. O experimento foi instalado em janeiro de 2008 .

Após a coleta, as estacas foram acondicionadas numa caixa contendo $100 \mathrm{~L}$ de água e transportadas até a Universidade Tecnológica Federal do Paraná (UTFPR), Câmpus Pato Branco (26¹1'50” S; $52^{\circ} 41^{\prime} 26^{\prime \prime} \mathrm{W} ; 816 \mathrm{~m}$ de altitude), onde o experimento foi instalado em casa de vegetação com telado de $70 \%$ de sombreamento.

O delineamento experimental foi em blocos ao acaso, com quatro repetições, no esquema fatorial $4 \times 2$, constituindo-se de quatro concentrações de ácido indolbutírico - AIB (zero; 2.000; $4.000 \mathrm{e}$ $6.000 \mathrm{mg} \mathrm{L}-1)$ e dois procedimentos (corte vertical ou anelamento da estaca). A unidade experimental foi constituída por duas estacas lenhosas de jabuticabeira. O AIB foi diluído em $\mathrm{KCl} 5 \mathrm{M}$, utilizando $10 \%$ do volume final a ser preparado, e o restante ( $90 \%$ do volume final) foi completado com água destilada, após a diluição.

$\mathrm{Na}$ preparação das estacas, foi efetuado um corte longitudinal na porção basal, onde ocorreu oxidação. Em metade do número das estacas, foi realizado o procedimento do anelamento, pela retirada de um anel de casca de $1,5 \mathrm{~cm}$ de largura (local para a emissão das raízes), com canivete, na altura de $35 \mathrm{~cm}$ da base da estaca. $\mathrm{O}$ anelamento foi recoberto com fina camada de algodão e embebido na solução de AIB na concentração correspondente ao tratamento. Em seguida, os ramos foram acondicionados em frascos plásticos de $1 \mathrm{~L}$, contendo água. Nas demais estacas, fez-se corte dividindo a estaca em duas partes, da base até a altura de $35 \mathrm{~cm}$ (corte vertical). Em seguida, metade do caule cortado foi inserido em frasco plástico de $1 \mathrm{~L}$, contendo água, e a outra metade ficou externamente ao frasco e em contato direto com o substrato (local para a emissão de raízes). Esta parte foi umedecida na solução de AIB, na concentração correspondente ao tratamento.

O gargalo dos frascos plásticos contendo as estacas foi vedado com algodão e cera de abelha aquecida, sendo que o anelamento ou o início do corte vertical ficaram localizados de $1 \mathrm{a} 2 \mathrm{~cm}$ acima do gargalo dos frascos, em contato com o substrato. Por sua vez, os frascos foram acondicionados em vasos plásticos com capacidade de $30 \mathrm{~L}$, contendo substrato Plantmax ${ }^{\circledR}$ Hortaliças.

Para que fosse possível o reabastecimento de água para os frascos contendo as estacas, realizou-se a perfuração próximo ao gargalo do frasco enterrado e também na base de uma garrafa pet de dois litros, colocada exteriormente ao substrato, sendo ambos os frascos interligados por uma mangueira com 5 $\mathrm{mm}$ de diâmetro e $25 \mathrm{~cm}$ de comprimento. As extremidades da mangueira foram vedadas com resina epóxi, formando sistema de vasos comunicantes (Figura 1). A cada três ou quatro dias, foi realizado o reabastecimento de água na garrafa pet.

A avaliação do percentual de enraizamento foi realizada 180 dias após a implantação do experimento. Os dados foram transformados em $\sqrt{\mathrm{x}+0,5} \mathrm{e}$ submetidos à análise de variância $(P \leq 0,05)$, pelo programa computacional 'Genes' (Cruz, 2006). 
Experimento 2: Propagação de jabuticabeira por estacas apicais herbáceas

Para a execução do experimento, foi utilizado material vegetativo de uma planta nativa e adulta de jabuticabeira ( $P$. cauliflora). Foram coletados ramos apicais herbáceos do último ciclo de crescimento (comprimento de $10 \mathrm{~cm}$ ). Após a coleta, os ramos foram acondicionados em baldes contendo solução de polivinilpirolidona (PVP) a $3.000 \mathrm{mg} \mathrm{L}^{-1}$, até a utilização.

O delineamento experimental foi de blocos ao acaso, com quatro repetições, no esquema fatorial 5 x 2, constituindo-se de cinco concentrações de AIB (zero; 2.000; 4.000; 6.000 e $8.000 \mathrm{mg} \mathrm{L}-1$ ) e duas épocas de implantação (outubro e dezembro de 2007). A unidade experimental foi constituída por quinze estacas apicais herbáceas de jabuticabeira.

$\mathrm{Na}$ casa de vegetação foram preparadas as estacas apicais herbáceas de 2 a $3 \mathrm{~mm}$ de diâmetro e 5 a $7 \mathrm{~cm}$ de comprimento. Foram mantidas duas folhas inteiras na extremidade apical, e a base da estaca foi cortada em bisel, próximo a uma gema vegetativa. A seguir, as estacas foram tratadas com AIB em talco, na concentração correspondente ao tratamento, pelo contato de $1 \mathrm{~cm}$ da base. A concentração zero constou do contato da base da estaca em talco industrial sem AIB.

Após o tratamento com AIB, as estacas foram acondicionadas em bandejas plásticas com tampa de $20 \times 09 \times 15 \mathrm{~cm}\left(2.700 \mathrm{~cm}^{3}\right)$, contendo vermiculita como substrato, até a metade da bandeja (1.350 $\mathrm{cm} 3$ ), sendo esta previamente umedecida com água. As estacas foram colocadas no substrato até metade do seu comprimento. As embalagens contendo as estacas foram acondicionadas em casa de vegetação (modelo 'Poly Venlo' - Van der Hoeven) com temperatura controlada (mínima de $15^{\circ} \mathrm{C}$ e máxima de $28^{\circ} \mathrm{C}$ ), com sistema de aquecimento e resfriamento. Diariamente, a vermiculita foi umedecida com auxílio de um borrifador.

A avaliação do percentual de enraizamento foi realizada 180 dias após a implantação do experimento. Os dados foram transformados em $\sqrt{\mathrm{x}+0,5} \mathrm{e}$ submetidos à análise de variância $(P \leq 0,05)$, pelo programa computacional 'Genes' (Cruz, 2006).

\section{RESULTADOS E DISCUSSÃO}

\section{Experimento 1: Propagação de jabutica- beira por estacas lenhosas}

Para o percentual de enraizamento, não foi verificada interação significativa entre os fatores estudados (concentração de AIB x procedimento), nem significância para os fatores considerados isolada- mente (Tabela 1). Entretanto, os valores indicam que o enraizamento das estacas lenhosas é dependente da aplicação de AIB e foi maior quando conjugado com o procedimento corte vertical. Inclusive, a maior porcentagem de enraizamento $(50 \%)$ foi obtida no tratamento com corte vertical e a maior concentração de AIB (6.000 $\mathrm{mg} \mathrm{L}^{-1}$ ), o qual foi numericamente bem superior aos demais tratamentos.

De forma semelhante ao presente trabalho, Husen e Pal (2003) observaram que o corte vertical em estacas de teca (Tectona grandis), espécie lenhosa utilizada para obtenção de madeira, proporcionou aumento do enraizamento das mesmas, sendo máximo de $88 \%$, quando conjugado com a maior concentração de AIB (2.000 $\left.\mathrm{mg} \mathrm{L}^{-1}\right)$. Entretanto, estes autores utilizaram estacas herbáceas, oriundas de plantas de 1 ano de idade, ao contrário do presente trabalho, no qual foram utilizadas estacas lenhosas de grande porte, oriundas de plantas adultas.

Foi observado que a maioria das estacas de jabuticabeira não manteve suas folhas, inclusive aquelas que enraizaram. Portanto, parece que o potencial de enraizamento das estacas lenhosas de jabuticabeira não está relacionado com a manutenção das folhas.

$\mathrm{O}$ fato de ter sido obtido até $50 \%$ de enraizamento neste experimento deve ser considerado satisfatório, visto que, até o momento, o máximo de enraizamento de estacas foi de 60\% (DUARTE et al., 1997). Estes autores utilizaram estacas herbáceas de P. cauliflora, tratadas com $1.000 \mathrm{mg} \mathrm{L}^{-1}$ de AIB e mantidas em câmara de polietileno hermeticamente fechada, sob $50 \%$ de sombreamento. Os autores relatam que, nesta câmara, a temperatura do substrato foi mantida entre 30 e $35^{\circ} \mathrm{C}$, o que parece ter favorecido o enraizamento. Outros autores obtiveram percentuais de enraizamento de estacas de $P$. jaboticaba entre 30 e 40\% (SCARPARE FILHO et al., 1999; SCARPARE et al., 2002; PEREIRA et al., 2005), sempre utilizando estacas herbáceas. É importante salientar que, no atual trabalho, foram utilizadas estacas lenhosas de grande porte, para as quais os resultados são escassos na literatura, sendo documentado enraizamento nulo para este tipo de estaca em P. cauliflora (ANDERSEN;GOMES, 1976).

Experimento 2: Propagação de jabuticabeira por estacas apicais herbáceas

Para o percentual de enraizamento, não foi observada interação significativa entre os fatores estudados (concentrações de AIB x épocas), tampouco para os fatores considerados isoladamente. Na primeira época (outubro), houve maior porcentagem de enraizamento $(7,1 \%)$, embora não diferindo significativamente de dezembro (2,3\%) (Tabela 2$)$. 
Em outubro, logo após o término da frutificação, a jabuticabeira apresentava brotações novas, as quais foram utilizadas para confeccionar as estacas. Ao contrário, em dezembro, a planta não estava emitindo brotações, e as estacas apicais estavam mais lignificadas, o que pode ter prejudicado ainda mais o enraizamento. Além disso, Kachecheba (1976) observou que houve diferenças sazonais no enraizamento de cultivares de hibisco, relacionando isso ao conteúdo de auxinas nas estacas, o qual é maior durante o acelerado crescimento vegetativo da planta-matriz. Isto pode ter ocorrido também para a jabuticabeira neste experimento.

O percentual de enraizamento das estacas herbáceas de jabuticabeira foi baixo, no máximo de $10 \%$ (em outubro e utilizando concentração de 2.000 e $4.000 \mathrm{mg} \mathrm{L}^{-1}$ de AIB). Nesse sentido, observou-se que apenas estacas que mantiveram suas folhas durante todo o período do experimento, formaram calo e/ou enraizaram. Assim, o enraizamento de estacas herbáceas de jabuticabeira parece ter relação com a manutenção das folhas na estaca, diferentemente do que ocorreu com as estacas lenhosas (experimento 1). Roberto et al. (2006) também observaram que estacas herbáceas de porta-enxertos de videira, nas quais foram mantidas as folhas, apresentaram maior percentual de enraizamento e de número de raízes, em relação a estacas nas quais as folhas foram retiradas no início do experimento. Segundo Couvillon (1988) as folhas auxiliam no enraizamento de estacas, pois são responsáveis por produzir auxinas e carboidratos, os quais continuam a ser sintetizados através da fotossíntese durante a permanência das estacas no substrato.

Observou-se que as maiores porcentagens de enraizamento, embora sem apresentar diferença significativa, foram obtidas com a utilização de 2.000 e $4.000 \mathrm{mg} \mathrm{L}^{-1}$ de AIB (6,7\%), decrescendo com 6.000 e $8.000 \mathrm{mg} \mathrm{L}^{-1}$ (4,2 e $2,5 \%$, respectivamente), o que demonstra efeito de inibição ocorrido nestas concentrações. Este efeito não foi observado nas estacas lenhosas de jabuticabeira, visto que o enraizamento foi crescente com as concentrações de AIB (experimento 1). Isto ocorreu porque estacas menos lignificadas requerem menor estímulo pela aplicação exógena de auxinas do que as lenhosas, tanto para iniciar quanto para expressar inibição do enraizamento (GONZÁLEZ; SCHIMIDT, 1992). De forma semelhante ao presente trabalho, Scarpare et al. (2002) observaram redução do enraizamento de estacas apicais herbáceas de jabuticabeira 'Sabará' (P. jaboticaba), com a utilização de concentrações de AIB superiores a $6.000 \mathrm{mg} \mathrm{L}^{-1}$.

Alguns trabalhos na literatura indicam o baixo percentual de enraizamento de estacas de jabuticabeira, se comparado com o de outras fruteiras. Por exemplo, Leonel et al. (1991), estudando o efeito da aplicação de auxinas e ácido bórico, observaram apenas a formação de calo na base de estacas semilenhosas de $P$. cauliflora, sem haver enraizamento. Por outro lado, Scarpare Filho et al. (1999) obtiveram enraizamento de até $38 \%$ de estacas de $P$. jaboticaba oriundas de brotações novas, após poda drástica da planta-matriz; e Duarte et al. (1997) verificaram até $60 \%$ de enraizamento de estacas apicais herbáceas de jabuticabeira (Plinia cauliflora), tratadas com 1.000 $\mathrm{mg} \mathrm{L}^{-1}$ de AIB e submetidas à câmara de polietileno hermeticamente fechada sob $50 \%$ de sombreamento. Para Pereira et al. (2005), o enraizamento das estacas apicais de jabuticabeira 'Sabará' ( $P$. jaboticaba) foi de até $39,6 \%$, sendo influenciada pelos valores de $\mathrm{pH}$ do substrato.

Observa-se, portanto, que já foram obtidos percentuais consideráveis de enraizamento de estacas de jabuticabeira, principalmente as herbáceas, considerando a dificuldade para tal. Entretanto, ainda são necessários mais trabalhos com o intuito de proporcionar aumento no percentual de enraizamento de estacas e desenvolver uma metodologia que facilite a propagação de mudas em larga escala.

Nesse sentido, em novos trabalhos, deve-se levar em consideração a importância do rejuvenescimento dos tecidos vegetais para a propagação de espécies de difícil enraizamento de estacas, como é o caso da jabuticabeira. Por isso, seria indicado testar pré-tratamentos das plantas-matrizes como o uso de poda drástica combinado com o estiolamento (Biasi, 1996), visando ao rejuvenescimento dos tecidos. Além disso, testar a eficiência da aplicação de ácidos fenólicos favorece o enraizamento quando conjugados com a aplicação de auxinas (KLEIN et al., 2000; TOFANELLI et al., 2004) e do aquecimento do substrato, conforme sugerido por Duarte et al. (1997), objetivando incrementar o enraizamento de estacas herbáceas de jabuticabeira.

A utilização de estacas lenhosas proporcionou até $50 \%$ de enraizamento, na concentração de $6.000 \mathrm{mg} \mathrm{L}^{-1}$ de AIB conjugada com corte vertical do ramo, o que demonstra bom potencial para propagação por estaquia de jabuticabeira, porém em pequena escala, devido a dificuldades inerentes ao processo. Além disso, se comparado com a alporquia, o método da estaquia lenhosa causa o mesmo dano à planta-matriz, é mais trabalhoso para realização e também mais oneroso, devido à infraestrutura e à alta concentração de AIB necessária. Por sua vez, a alporquia apresenta alto nível de enraizamento e pode ser realizada sem a utilização de AIB, quando efetuada em dezembro, coincidindo com período de intensa brotação e após a frutificação da planta-matriz (Danner et al., 2006). 


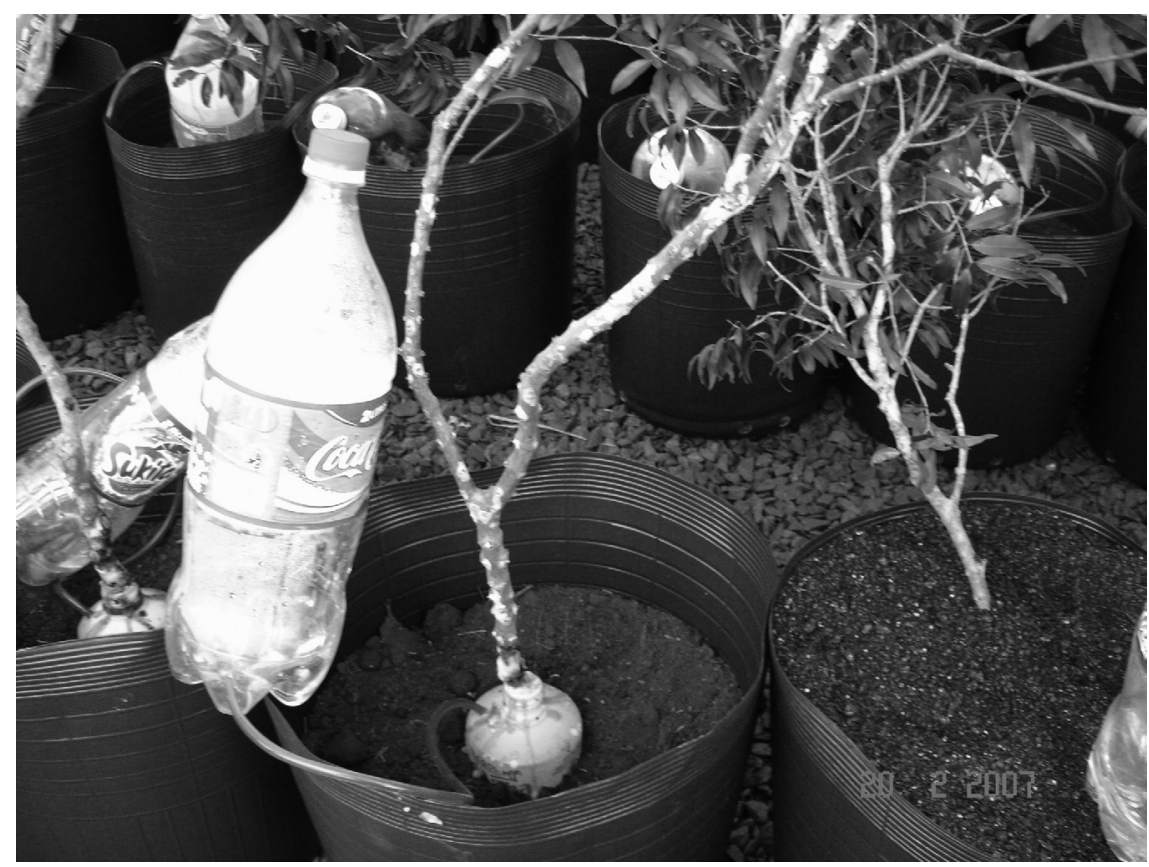

FIGURA 1 - Aspecto geral do acondicionamento das estacas lenhosas de jabuticabeira (Plinia cauliflora). UTFPR, Câmpus Pato Branco, 2009.

TABELA 1 - Enraizamento de estacas lenhosas de jabuticabeira (Plinia cauliflora) em diferentes concentrações de AIB ( $\left.\mathrm{mg} \mathrm{L}^{-1}\right)$ e procedimentos realizados na estaca (anelamento ou corte vertical). UTFPR, Câmpus Pato Branco, 2009.

\begin{tabular}{|c|c|c|c|c|c|}
\hline \multirow[b]{2}{*}{ Procedimento } & \multicolumn{4}{|c|}{ Concentração AIB $\left(\mathrm{mg} \mathrm{L}^{-1}\right)$} & \multirow[b]{2}{*}{ Média } \\
\hline & Zero & 2000 & 4000 & 6000 & \\
\hline Anelamento & 0,0 & 12,5 & 12,5 & 12,5 & $9,4^{\mathrm{NS}}$ \\
\hline Corte vertical & 0,0 & 12,5 & 25,0 & 50,0 & 21,9 \\
\hline Média & $0,0^{\mathrm{NS}}$ & 12,5 & 18,8 & 31,3 & $\mathrm{CV}(\%)=101,4$ \\
\hline
\end{tabular}

Ns: Não significativo pelo teste $\mathrm{F}(P \leq 0,05)$.

TABELA 2 - Enraizamento de estacas apicais herbáceas de jabuticabeira (Plinia cauliflora) em diferentes concentrações de AIB (mg L$\left.{ }^{-1}\right)$ e épocas de coleta. UTFPR, Câmpus Pato Branco, 2009.

\begin{tabular}{|c|c|c|c|c|c|c|}
\hline \multirow[b]{2}{*}{ Época } & \multicolumn{5}{|c|}{ Concentração AIB (mg L L } & \multirow[b]{2}{*}{ Média } \\
\hline & Zero & 2.000 & 4.000 & 6.000 & 8.000 & \\
\hline Outubro & 3,3 & 10,0 & 10,0 & 5,0 & 3,3 & $7,1^{\mathrm{NS}}$ \\
\hline Dezembro & 0,0 & 3,3 & 3,3 & 3,3 & 1,7 & 2,3 \\
\hline Média & $1,7^{\mathrm{NS}}$ & 6,7 & 6,7 & 4,2 & 2,5 & $\mathrm{CV}(\%)=86,6$ \\
\hline
\end{tabular}

Ns: Não significativo pelo teste $\mathrm{F}(P \leq 0,05)$. 


\section{CONCLUSÃO}

Nas condições em que este trabalho foi desenvolvido, pode-se concluir que:

Estacas lenhosas de jabuticabeira, tratadas com AIB, são mais eficazes no enraizamento do que as estacas herbáceas.

\section{REFERÊNCIAS}

CASAGRANDE JÚNIOR, J.G.; DUTRA, L.F.; TONIETTO, A.; NACHTIGAL, J.C.; STRELOW, E. Efeito do estiolamento de ramos e do AIB no enraizamento de estacas herbáceas de jabuticabeira. Revista Brasileira de Agrociência, Pelotas, v.6, n.1, p.24-26, 2000.

CRUZ, C.D. Programa genes: estatística experimental e matrizes. Viçosa: UFV, 2006. 285p.

DANNER, M.A.; CITADIN, I.; JUNIOR, A.A.F.; ASSMAN, A.P.; MAZARO, S.M.; DONAZZOLO, J.; SASSO, S.A.Z. Enraizamento de jabuticabeira (Plinia trunciflora) por mergulhia aérea. Revista Brasileira de Fruticultura, Jaboticabal, v.28, n.3, p.530-532, 2006

DANNER, M.A.; SASSO, S.A.Z.; CITADIN, I.; AMBROSIO, R.; SACHET, M.R.; MAZARO, S.M. Variabilidade da qualidade de frutos de jabuticabeiras de diferentes sítios de ocorrência da região sudoeste do Paraná. In: CONGRESSO BRASILEIRO DE FRUTICULTURA, 20., 2008, Vitória. Anais... Vitória: Sociedade Brasileira de Fruticultura, 2008. 1 CD-ROM.

DEMATTÊ, M.E.S.P. Ornamental use of Brazilian Myrtaceae. Acta Horticulturae, Wageningen, n.452, p.143-179, 1997.

DeVIER, C.L.; GENEVE, R.L. Flowering influences adventitious root formation in chrysanthemum cuttings. Scientia Horticulturae, Amsterdam, v.70, p.309-318, 1997.

DUARTE, O.R.; HUETE, M.; LÜDDER, S.P. Propagation of jabuticaba (Myrciaria cauliflora (Mart.) Berg.) by terminal leafy cuttings. Acta Horticulturae, Wageningen, n.452, p.123-128, 1997.
HAGIWARA, A.; MIYASHITA, K.; NAKANISHI, T.; SANO, M.; TAMANO, S.; KADOTA, T.; KODA, T.; NAKAMURA, M.; IMAIDA, K.; ITO, N.; SHIRAI, T. Pronounced inhibition by a natural anthocyanin, purple corn color, of 2-amino-16phenylimidazol (4,5-b) pyridine (PhIP)-associated colorectal carcinogenesis in male F344 rats pretreated with 1,2- dimethylhydrazine. Cancer Letters, Oxford, v.171, n.1, p.17-25, 2001

HUSEN, A.; PAL, M. Metabolic changes during adventitious root primordium development in Tectona grandis Linn. f. (teak) cuttings as affected by age of donor plants and auxin (IBA and NAA) treatment. New Forests, Sydney, v.33, n.3, p.309-323, 2007.

KAPADIA, G.J.; BALASUBRAMANIAN, V.; TOKUDA, H.I.; WASHINA, A.; NISHINO, H. Inhibition of 12-O-tetradecanoylphorbol-13-acetate induced Epstein virus early antigen activation by natural colorants. Cancer Letters, Oxford, v.115, n.2, p.173-178, 1997.

LEONEL, S.; VARASQUIM, L.T.; RODRIGUES, J.D.; CEREDA, E. Efeito da aplicação de fitorreguladores e ácido bórico em estacas de jabuticabeira (Myrciaria cauliflora Berg.). Revista Brasileira de Fruticultura, Jaboticabal, v.13, n.3, p.219- 222, 1991.

MAGALHÃES, M.M.; BARROS, R.S.; FINGER, F.L. Changes in non-structural carbohydrates in developing fruit of Myrciaria jaboticaba. Scentia Horticulturae, Amsterdam, v.66, n.1-2, p.17-22, 1996.

MATTOS, J.L.R. Fruteiras nativas do Brasil: jaboticabeiras. Porto Alegre: Nobel, 1983. 92p.

MENDONÇA, R.M.N. Maturação, secagem e armazenamento de sementes e propagação vegetativa de jabuticabeiras (Myrciaria $\mathrm{sp}$ ). 2000. 136 f. Tese (Doutorado em Agronomia) - Universidade Federal de Viçosa, Viçosa, MG, 2000.

PACHECO, A.C.; CASTRO, P.R.C.; APPEZZETODA-GLÓRIA, B. Aspectos anatômicos do enraizamento da videira muscadínia (Vitis rotundifolia Michx.) através de alporquia. Scientia Agrícola, Piracicaba, v.55, n.2, p.210-217, 1998. 
PEREIRA, M.; OLIVEIRA, A.L.; GONÇALVES, A.N.; ALMEIDA, M. Efeitos de substratos, valores de $\mathrm{pH}$ e concentrações de AIB no enraizamento de estacas apicais de jabuticabeira [Myrciaria jabotica$b a$ (Vell) O. Berg.]. Scientia Florestalis, Piracicaba, n.69, p.84-92, 2005.

PIETTA, P. Flavonoids as antioxidants. Journal of Natural Products, Cincinnati, v.63, n.7, p.10351042, 2000.

SAMPAIO, V.R. Propagação por enxertia do Sabarazeiro. Anais da ESALQ, Piracicaba, v.41, n.1, p.135-140, 1984.

SCARPARE FILHO, J.A.; NETO, J.T.; COSTA, J.W.H.; KLUGE, R.A. Efeito do ácido indolbutírico no enraizamento de estacas herbáceas de jabuticabeira 'Sabará' (Myrciaria jabuticaba), em condições de nebulização. Revista Brasileira de Fruticultura, Jaboticabal, v.21, n.2, p.146-149, 1999.
SCARPARE F.V.; KLUGE, R.A.; SCARPARE FILHO, J.A.; BORBA, M.R.C. Propagação da jabuticabeira 'Sabará' (Myrciaria jaboticaba (Vell.) Berg.) através de estacas caulinares. In: CONGRESSO BRASILEIRO DE FRUTICULTURA, 17., 2002, Belém. Anais... Belém: Sociedade Brasileira de Fruticultura, 2002.

TEIXEIRA, L.N.; STRINGHETA, P.C.; OLIVEIRA, F.A. Comparação de métodos para quantificação de antocianinas. Ceres, Viçosa, v.55, n.4, p.297-304, 2008 .

WANG, C.J.; WANG, J.M.; LIN, W.L.; CHU, C.Y.; CHOU, F.P.; TSENG, T.H. Protective effect of Hibiscus anthocyanins against tert-butyl hidroperoxideinduced hepatic toxicity in rats. Food and Chemical Toxicology, Oxford, v.38, n.5, p.411-416, 2000.

WIESMAN, Z.; LAVEE, S. Relationship of carbohydrate sources and indole-3-butyric acid in olive cuttings. Australian Journal of Plant Physiology, Melbourne, v.22, n.5, p.811-816, 1995. 